\title{
Fibrinogen, chronic obstructive pulmonary disease (COPD) and outcomes in two United States cohorts
}

This article was published in the following Dove Press journal:

International Journal of COPD

6 March 2012

Number of times this article has been viewed

\author{
Deepa Valvi' \\ David M Mannino ${ }^{1,2}$ \\ Hana Müllerova ${ }^{3}$ \\ Ruth Tal-Singer ${ }^{4}$ \\ 'Department of Preventive Medicine \\ and Environmental Health, University \\ of Kentucky College of Public Health, \\ Lexington, KY, USA; ${ }^{2}$ Department \\ of Pulmonary, Critical Care, and Sleep \\ Medicine, University of Kentucky \\ College of Medicine, Lexington, KY, \\ USA; ${ }^{3}$ GlaxoSmithKline Research \\ and Development, Worldwide \\ Epidemiology, Stockley Park, \\ Middlesex, UK; ${ }^{4}$ GlaxoSmithKline \\ Research and Development, \\ Respiratory Therapy Area Unit, \\ King of Prussia, PA, USA
}

Correspondence: David M Mannino Department of Preventive Medicine and Environmental Health, University of Kentucky College of Public Health, I 2 I Washington Avenue, Lexington, KY 40536, USA

Tel +l 8592182099

Email dmannino@uky.edu
Background: Fibrinogen is a marker of systemic inflammation and may be important in the pathogenesis and progression of chronic obstructive pulmonary disease (COPD).

Methods: We used baseline data from Atherosclerosis Risk in Communities and Cardiovascular Health Studies to determine the relation between fibrinogen levels and COPD and to examine how fibrinogen levels at baseline affected outcomes of death, development of COPD, lung function decline, and COPD-hospitalizations.

Results: Our study sample included 20,192 subjects, of whom 2995 died during the follow-up period. The mean fibrinogen level was $307.6 \mathrm{mg} / \mathrm{dL}$ and $10 \%$ of the sample had levels $>393.0 \mathrm{mg} / \mathrm{dL}$. Subjects with Stage 3 or 4 COPD were more likely to have a fibrinogen level $>393.0 \mathrm{mg} / \mathrm{dL}$ (odds ratio $2.28,95 \%$ confidence interval [CI]: 1.79-2.95). In the longitudinal adjusted models, fibrinogen levels $>393 \mathrm{mg} / \mathrm{dL}$ predicted mortality (hazards ratio $1.54,95 \%$ CI: 1.39-1.70), COPD-related hospitalization (hazards ratio 1.45, 95\% CI: $1.27-1.67$ ), and incident Stage 2 COPD (odds ratio 1.36, 95\% CI: 1.07-1.74). Similar findings were seen with continuous fibrinogen levels.

Conclusion: In the Atherosclerosis Risk in Communities/Cardiovascular Health Studies cohort data, higher fibrinogen levels are predictors of mortality, COPD-related hospitalizations, and incident Stage 2 COPD.

Keywords: COPD, fibrinogen, epidemiology, mortality, hospitalization

\section{Background}

Chronic obstructive pulmonary disease (COPD) is a heterogeneous disease with varied clinical presentations. ${ }^{1}$ COPD became the third leading cause of death in the United States in 2008. ${ }^{2}$ Approximately one in 20 deaths in the United States had COPD as the underlying cause. ${ }^{2}$ Understanding the natural history of COPD has been important in the field of pulmonary medicine, dating back to the work of Burrows et al, ${ }^{3}$ and Fletcher et al. ${ }^{4}$ Over subsequent years researchers have championed different hypotheses about COPD development, including the British hypothesis stating that the presence of cough and sputum was the key factor ${ }^{5}$ and the Dutch hypothesis stating that the presence of increased airways responsiveness was the major factor. ${ }^{6}$

Fibrinogen is an inflammatory marker that is increased in COPD, as well as many other inflammation-associated diseases. ${ }^{7}$ The Coronary Artery Risk Development in Young Adults CARDIA study showed fibrinogen as a marker for chronic lowgrade inflammation and is associated with modest deterioration of lung function in healthy young adults. ${ }^{8}$ According to Dahl and colleagues, increased levels of fibrinogen were associated with reduced lung function and increased risk of COPD, 
and these associations were independent of smoking status. ${ }^{9}$ Groenewegen and colleagues demonstrated that besides lung function impairment systemic inflammation manifested by elevated fibrinogen levels was an independent risk factor for exacerbations of COPD. ${ }^{10}$ Hyperfibrinogenemia is linked with asthma ${ }^{11}$ and smoking. ${ }^{12}$ There is little information on the relationship between plasma fibrinogen levels and lung function decline ${ }^{8}$ although recent work has suggested that systemic processes may be important in these processes.

We hypothesized that fibrinogen can be used as a tool for stratifying COPD patients in clinical trials by identifying populations at higher risk for poor outcomes such as development of COPD, rapidly declining lung function, COPD hospitalizations, and death. This paper examines the descriptors of normal and elevated fibrinogen levels at baseline in a cohort of US adults and determines the relationship between elevated fibrinogen levels and incident respiratory outcomes including development of COPD, rapidly declining lung function, COPD hospitalizations, and death controlling other risk factors, including cardiovascular disease (CVD).

\section{Methods}

\section{Study population}

The study population originated from the combined cohorts of the Atherosclerosis Risk in Communities (ARIC) and Cardiovascular Health Study (CHS). Both the ARIC and CHS were population-based National Institute of Health cohorts initiated in the late $1980 \mathrm{~s}$.

The ARIC study was initiated in 1987 as a longitudinal, population-based study of the etiology and clinical sequelae of atherosclerosis in 15,792 adults. Study protocols were approved for protection of human subjects. Participants were selected from the entire population by probability sampling from four US communities: Forsyth County, NC; Minneapolis, $\mathrm{MN}$; Washington County, MD; and Jackson, MS (where only African Americans were sampled). Specific details of the ARIC study are published elsewhere. ${ }^{13}$ Our analysis was limited to ARIC participants aged 45-64 years old at baseline, who provided information on respiratory symptoms and diagnoses, medical history, and who underwent adequate pulmonary function testing at the baseline examination.

The original CHS cohort consisted of 5201 subjects selected using Medicare eligibility lists provided by the US Healthcare Financing Administration for four communities: Forsyth County, NC; Pittsburgh, PA; Sacramento County, CA; and Washington County, MD from May 1989 to May 1990. Analysis was limited to subjects who provided information on respiratory symptoms and diagnoses, medical history, and smoking status, and who underwent a clinical exam and spirometric testing at baseline and 4 years. Details of the CHS are published elsewhere. ${ }^{14}$

\section{Definition of variables}

Demographic data used in this analysis were age (in 5 year categories for ARIC and 4 year categories for CHS), sex, race (black, white, other), education (less than 12 years, 12 years, and more than 12 years). The study participants were categorized into normal and elevated fibrinogen values with a cut off value of greater than $393 \mathrm{mg} / \mathrm{dL}$ (corresponding to the top decile) and six lung function categories based on modified Global Initiative for Chronic Obstructive Lung Disease (GOLD) criteria; classification is based on "pre-bronchodilator" response. GOLD Stage 3 or 4 (forced expiratory volume in 1 second $\left(\mathrm{FEV}_{1}\right) /$ forced vital capacity $(\mathrm{FVC})<0.70$ and $\mathrm{FEV}_{1}<50 \%$ predicted), GOLD Stage $2\left(\mathrm{FEV}_{1} / \mathrm{FVC}<0.70\right.$ and $\mathrm{FEV}_{1}>50$ to $<80 \%$ predicted), GOLD Stage $1\left(\mathrm{FEV}_{1} /\right.$ $\mathrm{FVC}<0.70$ and $\mathrm{FEV}_{1}>80 \%$ ), restricted $\left(\mathrm{FEV}_{1} / \mathrm{FVC}>0.70\right.$ and FVC $<80 \%$ predicted), GOLD Stage 0 (presence of respiratory symptoms in the absence of any lung function abnormality), and no lung disease.

We included in the analyses potential confounders of CVD at baseline (subjects reporting a diagnosis of a previous myocardial infarction, stroke, heart failure, angina or transient ischemic attack, and excluding hypertension). Smoking status included current, former, and never smokers. Respondents with a positive response to "Have you ever smoked cigarettes?" and "Do you now smoke cigarettes?" were classified as "ever smokers" and "current smokers," respectively. Pipe or cigar smokers were also considered as "smokers." Subjects were classified as having diabetes if they reported either a diagnosis of diabetes at baseline or had impaired fasting or post-glucose load levels (140 mg/dL) upon examination. Body mass index was categorized as "Underweight" (<20), "Normal" (20-24), "Overweight" (25-29), and "Obese" ( $\geq 30)$.

\section{Laboratory methods - fibrinogen}

In ARIC, blood was drawn after an 8-hour fasting period with minimal trauma from an antecubital vein. Samples were processed by a standardized protocol and stored at $-70^{\circ} \mathrm{C}$ until assayed at the ARIC Hemostasis Laboratory at the University of Texas Medical School, Houston, TX. Detailed methods for blood processing and measurement of hemostatic variables have been published elsewhere. ${ }^{15}$ Fibrinogen was measured by the thrombin-time titration method. ${ }^{16}$ Reliability coefficients 
obtained from repeated testing of individuals over several weeks were 0.72 for fibrinogen. ${ }^{16}$

In CHS, baseline fibrinogen levels in 1989-1990 were measured with a BBL fibrometer (Becton Dickinson, Cockeysville, MD) by the Clauss methods with Dade fibrinogen calibration reference (Baxter-Dade, Bedford, MA) and bovine thrombin (Parke-Davis, Lititz, PA). ${ }^{17}$

\section{Pulmonary function testing}

In both studies, spirometry was conducted using a volume displacement, water-sealed spirometer. At least three acceptable spirograms were obtained from a minimum of five forced expirations. The best single spirogram was identified by computer and confirmed by a technician. Quality assurance was provided by the CHS Pulmonary Function Center for CHS and the ARIC investigators for ARIC, and the procedures followed contemporary American Thoracic Society guidelines. ${ }^{18}$ Several measures of lung function were used in this analysis: the $\mathrm{FEV}_{1}$, the $\mathrm{FVC}$, and the $\mathrm{FEV}_{1} / \mathrm{FVC}$ ratio. We used the prediction equations derived from the Third National Health and Nutrition Examination Survey to define the predicted values of $\mathrm{FEV}_{1}$ and $\mathrm{FVC} .{ }^{19}$ We defined a subject as having a respiratory symptom if they reported cough, phlegm, dyspnea, or wheeze.

\section{Definition of outcomes}

Death was defined as all-cause mortality. COPD-related hospitalizations were people with hospitalization code of ICD-9 490-496 at any time after baseline. Rapidly declining lung function comprised of people who, between the first and second spirometries, were in the highest quartile of $\mathrm{FEV}_{1}$ decline (determined as an absolute difference in the baseline minus the follow-up $\mathrm{FEV}_{1}$ and divided by the interval between the two tests to obtain $\mathrm{FEV}_{1}$ loss per year). Lung function decline was also determined as a proportion of the baseline $\mathrm{FEV}_{1}$ and relative to the predicted $\mathrm{FEV}_{1}$ at baseline, but only the absolute difference was used in the analyses. We also determined the proportion of people who were unable to obtain a follow-up spirometry. The development of COPD was defined as GOLD Stage 2 or higher disease in people who at baseline did not have GOLD Stage 2 or higher disease.

\section{Statistical analyses}

Data analysis was completed with SAS (v 9.2; SAS Institute, Cary, NC) and SUDAAN (v 9.0; RTI, Research Triangle Park, NC). Descriptive statistics and frequency distributions were calculated for the studied population and its relationship to fibrinogen levels and predictors (GOLD Status, CVD, smoking status, diabetes mellitus). Linear regression model using SUDAAN procedure REGRESS was used to determine correlates of fibrinogen levels controlling for age, sex, race/ethnicity, body mass index, smoking status, modified GOLD stage, diabetes, CVD, and educational level. These were replicated examining fibrinogen levels in the top decile ( $>393.0 \mathrm{mg} / \mathrm{dL}$ ) using the SUDAAN procedure RLOGIST, controlling for these same potential confounders. Our primary outcome of interest in the survival models was time to death and COPD-related hospitalization. Cox proportional hazard regression models were developed using the SUDAAN procedure SURVIVAL to account for differential follow-up in cohort participants. (Censoring occurred at the date of death on certificate or the date the participant was last known to be alive for mortality, and date of hospitalization or date last known to be alive for COPD-related hospitalization.) The SUDAAN procedure RLOGIST was used to determine the relation between fibrinogen levels and elevated fibrinogen levels and not having a follow-up spirometry, being in the highest quartile of $\mathrm{FEV}_{1}$ decline, and having incident COPD.

\section{Results}

The combined cohorts of ARIC and CHS included 20,993 participants at baseline. We excluded 311 who had not obtained fibrinogen levels, 209 who did not have pulmonary function testing done, and 281 subjects missing other key baseline data leaving 20,192 subjects in the combined cohorts. The mean follow-up time was 9.7 years, with a maximum of 12.1 years. By the end of the follow-up time, 2995 subjects $(14.8 \%)$ had died.

Table 1 shows the distribution of age, sex, race/ethnicity, body mass index, smoking status, modified GOLD stage, diabetes mellitus, CVD, and educational level, including the actual numbers of studied subjects and the percentage. This Table also reports the mean fibrinogen levels, the proportion of subjects with fibrinogen levels $>393.0 \mathrm{mg} / \mathrm{dL}$, and the deaths per 1000 person-years of follow-up.

Tables 2 and 3 report the correlates of fibrinogen levels (Table 2) and the correlates of elevated fibrinogen levels (Table 3). There was considerable overlap between these two analyses; for example, in both analyses older age, current smoking, and the presence of diabetes or CVD were associated with higher fibrinogen levels. The presence of severe or very severe COPD was one of the strongest predictors of fibrinogen levels, with a mean increase of $24.71 \mathrm{mg} / \mathrm{dL}$ (standard error $3.13 \mathrm{mg} / \mathrm{dL}$ ) in the linear regression models and an odds ratio for elevated fibrinogen of 2.28 (95\% confidence interval: 1.79-2.95). 
Table I Demographic characteristics and fibrinogen levels of subjects included in the analysis

\begin{tabular}{|c|c|c|c|c|c|}
\hline Covariate & $\mathbf{n}$ & $\%$ & $\begin{array}{l}\text { Mean fibrinogen level in } \\
\text { mg/dL (standard error) }\end{array}$ & $\begin{array}{l}\text { Proportion with } \\
\text { fibrinogen }>393.0 \mathrm{mg} / \mathrm{dL}\end{array}$ & $\begin{array}{l}\text { Deaths per } \\
1000 \text { person years }\end{array}$ \\
\hline \multicolumn{6}{|l|}{ Age } \\
\hline $45-49$ & 4072 & 20.2 & $292.5(1.0)$ & 6.6 & 3.8 \\
\hline $50-54$ & 3968 & 19.7 & $301.1(1.0)$ & 8.5 & 6.3 \\
\hline $55-59$ & 3739 & 18.5 & $308.6(1.1)$ & 9.5 & 10.7 \\
\hline $60-64$ & 3507 & 17.4 & $313.2(1.1)$ & 10.6 & 17.6 \\
\hline $65-68$ & 1279 & 6.3 & $316.0(1.1)$ & 11.6 & 18.3 \\
\hline $69-72$ & 1465 & 7.3 & 319.8 (1.7) & 13.9 & 26.0 \\
\hline $73-76$ & 973 & 4.8 & 318.9 (1.9) & 12.5 & 37.0 \\
\hline $77-80$ & 690 & 3.4 & $324.0(2.6)$ & 15.5 & 60.0 \\
\hline$>80$ & 499 & 2.5 & $333.9(4.8)$ & 18.2 & 108.5 \\
\hline \multicolumn{6}{|l|}{ Sex } \\
\hline Male & 9011 & 44.6 & $302.9(0.7)$ & 9.2 & 19.8 \\
\hline Female & $|I| 8 \mid$, & 55.4 & $311.4(0.6)$ & 10.5 & 11.8 \\
\hline \multicolumn{6}{|l|}{ Race-ethnicity } \\
\hline White & 16,027 & 79.4 & $304.1(0.5)$ & 8.7 & 15.4 \\
\hline Black & 4165 & 20.6 & $321.0(1.1)$ & 14.9 & 15.0 \\
\hline \multicolumn{6}{|l|}{ Body mass index } \\
\hline$<20$ & 800 & 4.0 & $301.9(2.5)$ & 9.6 & 28.2 \\
\hline $20-25$ & 6263 & 31.0 & $297.7(0.8)$ & 7.7 & 15.2 \\
\hline $25-30$ & 8073 & 40.0 & $305.8(0.7)$ & 9.1 & I5.I \\
\hline$>30$ & 5056 & 25.0 & $323.8(1.0)$ & 14.2 & 13.7 \\
\hline \multicolumn{6}{|l|}{ Smoking status } \\
\hline Current smoker & 4929 & 24.4 & $323.4(1.0)$ & 14.2 & 18.6 \\
\hline Former smoker & 7036 & 34.9 & $302.1(0.8)$ & 8.9 & 16.9 \\
\hline Never smoker & 8227 & 40.7 & $303.0(0.7)$ & 8.2 & 12.0 \\
\hline \multicolumn{6}{|c|}{ Modified GOLD stage } \\
\hline Stage 3 or 4 & 585 & 2.9 & $336.8(3.1)$ & 19.3 & 54.6 \\
\hline Stage 2 & 2221 & 11.0 & 320.7 (I.5) & 14.1 & 25.3 \\
\hline Stage I & 2669 & 13.2 & $309.5(1.3)$ & 11.3 & 23.2 \\
\hline Symptoms only & 4375 & 21.7 & $306.0(1.0)$ & 14.0 & 13.2 \\
\hline Restrictive & 3071 & 15.2 & $324.2(1.3)$ & 9.3 & 15.8 \\
\hline None & $727 \mid$ & 36.0 & $294.6(0.7)$ & 6.1 & 8.2 \\
\hline \multicolumn{6}{|l|}{ Diabetes mellitus } \\
\hline Yes & 2519 & 12.5 & $328.3(1.5)$ & 16.8 & 32.6 \\
\hline No & 17,673 & 87.5 & $304.7(0.5)$ & 9.0 & 13.1 \\
\hline \multicolumn{6}{|c|}{ Cardiovascular disease } \\
\hline Yes & 3076 & 15.3 & $320.4(1.3)$ & 14.0 & 33.3 \\
\hline No & 17,116 & 84.8 & $305.3(0.5)$ & 9.2 & 12.4 \\
\hline \multicolumn{6}{|l|}{ Education level } \\
\hline$<12$ & 4937 & 24.5 & $322.1(1.0)$ & 14.1 & 24.3 \\
\hline 12 years & 6366 & 31.5 & $307.0(0.8)$ & 9.5 & 12.4 \\
\hline$>13$ years & 8889 & 44.0 & $300.0(0.8)$ & 7.9 & 12.7 \\
\hline Total & 20,192 & 100.0 & $307.6(0.5)$ & 9.9 & 15.1 \\
\hline
\end{tabular}

Table 4 shows the proportion of participants with the outcomes of interest. During follow-up, $14.8 \%$ of the cohort died, $7.5 \%$ experienced a COPD-related hospitalization, and $16.3 \%$ did not obtain a follow-up spirometry. The table also shows 16,935 subjects had a follow-up spirometry and of these, 14,848 did not have Stage 2 or higher COPD at baseline. Of the latter, $4.9 \%$ were found to have Stage 2 or higher COPD in follow-up.

The quartiles of lung function change are displayed in Table 5. The most rapidly declining quartile lost $127 \mathrm{~mL}$ of $\mathrm{FEV}_{1}$ annually, corresponding to $4.7 \%$ (annually) of their baseline value and $4.3 \%$ of their predicted baseline value.

Table 6 displays the unadjusted and fully adjusted models for either continuous fibrinogen or elevated fibrinogen (>393 mg/dL) predicting death, COPD-related hospitalization, missing spirometry, rapidly declining lung function, and incident COPD. Fibrinogen was a significant predictor of all of these outcomes with the exception of being in the most rapidly declining $\mathrm{FEV}_{1}$ quartile. 
Table 2 Correlates of fibrinogen levels from linear regression models $(n=20,192)$

\begin{tabular}{|c|c|c|c|}
\hline Covariate & $\begin{array}{l}\text { Beta } \\
\text { estimate }\end{array}$ & $\begin{array}{l}\text { Standard } \\
\text { error }\end{array}$ & $P$-value \\
\hline \multicolumn{4}{|l|}{ Age } \\
\hline $45-49$ & 0 & 0 & \\
\hline $50-54$ & 7.60 & 1.32 & $<0.001$ \\
\hline $55-59$ & 14.82 & 1.39 & $<0.001$ \\
\hline $60-64$ & 19.06 & 1.43 & $<0.001$ \\
\hline $65-68$ & $25.7 I$ & 1.97 & $<0.001$ \\
\hline $69-72$ & 30.90 & 1.95 & $<0.001$ \\
\hline $73-76$ & 31.74 & 2.21 & $<0.001$ \\
\hline $77-80$ & 38.02 & 2.83 & $<0.001$ \\
\hline$>80$ & 51.44 & 3.51 & $<0.001$ \\
\hline \multicolumn{4}{|l|}{ Sex } \\
\hline Male & -7.36 & 1.01 & $<0.001$ \\
\hline Female & 0 & 0 & \\
\hline \multicolumn{4}{|l|}{ Race-ethnicity } \\
\hline White & 0 & 0 & \\
\hline Black & 15.39 & 1.24 & $<0.001$ \\
\hline \multicolumn{4}{|l|}{ Body mass index } \\
\hline$<20$ & -5.88 & 2.47 & 0.017 \\
\hline $20-25$ & 0 & 0 & \\
\hline $25-30$ & 9.58 & 1.04 & $<0.001$ \\
\hline$>30$ & 24.63 & 1.24 & $<0.001$ \\
\hline \multicolumn{4}{|l|}{ Smoking status } \\
\hline Current smoker & 25.60 & 1.23 & $<0.001$ \\
\hline Former smoker & 1.64 & 1.04 & 0.116 \\
\hline Never smoker & 0 & 0 & \\
\hline \multicolumn{4}{|l|}{ GOLD stage } \\
\hline Stage 3 or 4 & 24.71 & 3.13 & $<0.001$ \\
\hline Stage 2 & 12.04 & 1.66 & $<0.001$ \\
\hline Stage I & 7.68 & 1.48 & $<0.001$ \\
\hline Symptoms only & 15.44 & 1.47 & $<0.001$ \\
\hline Restrictive & 3.05 & 1.17 & 0.009 \\
\hline None & 0 & 0 & \\
\hline \multicolumn{4}{|l|}{ Diabetes mellitus } \\
\hline Yes & 11.22 & 1.55 & $<0.001$ \\
\hline No & 0 & 0 & \\
\hline \multicolumn{4}{|c|}{ Cardiovascular disease } \\
\hline Yes & 8.19 & 1.34 & $<0.001$ \\
\hline No & 0 & 0 & \\
\hline \multicolumn{4}{|l|}{ Education level } \\
\hline$<12$ & 7.46 & 1.21 & $<0.001$ \\
\hline 12 years & 3.90 & 1.01 & $<0.001$ \\
\hline$>13$ years & 0 & 0 & \\
\hline
\end{tabular}

Figures 1-3 depict the interaction between fibrinogen levels $>393 \mathrm{mg} / \mathrm{dL}$ and modified GOLD stage in predicting mortality, COPD-related hospitalization, and incident COPD.

\section{Discussion}

This analysis determined that fibrinogen levels were related to spirometrically determined obstructive lung disease, with evidence of a dose-response effect for COPD. Subjects with
Table 3 Correlates of fibrinogen levels $>393 \mathrm{mg} / \mathrm{dL}$ (top decile) from logistic regression models $(n=20,192)$

\begin{tabular}{|c|c|c|}
\hline Covariate & Odds ratio & $\begin{array}{l}95 \% \text { confidence } \\
\text { interval }\end{array}$ \\
\hline \multicolumn{3}{|l|}{ Age } \\
\hline $45-49$ & 1.00 & 1.00 \\
\hline $50-54$ & 1.30 & $(1.09,1.54)$ \\
\hline $55-59$ & 1.42 & $(1.19,1.68)$ \\
\hline $60-64$ & 1.62 & $(1.36,1.93)$ \\
\hline $65-68$ & 2.01 & $(1.59,2.53)$ \\
\hline $69-72$ & 2.67 & $(2.16,3.30)$ \\
\hline $73-76$ & 2.44 & $(1.90,3.14)$ \\
\hline $77-80$ & 3.29 & $(2.51,4.29)$ \\
\hline$>80$ & 4.48 & $(3.36,5.98)$ \\
\hline \multicolumn{3}{|l|}{ Sex } \\
\hline Male & 0.93 & $(0.83,1.04)$ \\
\hline Female & 1.00 & 1.00 \\
\hline \multicolumn{3}{|l|}{ Race-ethnicity } \\
\hline White & 1.00 & 1.00 \\
\hline Black & 1.99 & $(1.77,2.24)$ \\
\hline \multicolumn{3}{|l|}{ Body mass index } \\
\hline$<20$ & 0.97 & $(0.74,1.26)$ \\
\hline $20-25$ & 1.00 & 1.00 \\
\hline $25-30$ & 1.23 & $(1.08,1.40)$ \\
\hline$>30$ & 1.91 & $(1.67,2.19)$ \\
\hline \multicolumn{3}{|l|}{ Smoking status } \\
\hline Current smoker & 2.12 & $(I .86,2.4 I)$ \\
\hline Former smoker & 1.16 & $(1.02,1.31)$ \\
\hline Never smoker & 1.00 & 1.00 \\
\hline \multicolumn{3}{|l|}{ GOLD stage } \\
\hline Stage 3 or 4 & 2.28 & $(1.79,2.95)$ \\
\hline Stage 2 & 1.77 & $(1.52,2.14)$ \\
\hline Stage I & 1.59 & $(1.34,1.88)$ \\
\hline Symptoms only & 1.77 & $(1.55,2.13)$ \\
\hline Restrictive & 1.23 & $(1.07,1.44)$ \\
\hline None & 1.00 & 1.00 \\
\hline \multicolumn{3}{|l|}{ Diabetes mellitus } \\
\hline Yes & 1.47 & $(1.29,1.67)$ \\
\hline No & 1.00 & 1.00 \\
\hline \multicolumn{3}{|c|}{ Cardiovascular disease } \\
\hline Yes & 1.29 & $(1.14,1.46)$ \\
\hline No & 1.00 & 1.00 \\
\hline \multicolumn{3}{|l|}{ Education level } \\
\hline$<12$ & 1.26 & $(\mathrm{I} .1 \mathrm{I}, \mathrm{I} .42)$ \\
\hline 12 Years & 1.18 & $(1.05,1.33)$ \\
\hline$>13$ years & 1.00 & 1.00 \\
\hline
\end{tabular}

more advanced COPD (Stages 3 or 4 ) had a greater elevation in fibrinogen $(24.71 \mathrm{mg} / \mathrm{dL}, P=0.0000)$ than GOLD Stage 2 or GOLD Stage 1 disease $(12.04 \mathrm{mg} / \mathrm{dL}, P=0.0000$ and $7.68 \mathrm{mg} / \mathrm{dL}, P=0.0000$ respectively), relative to people with normal lung function. In addition, we determined that higher fibrinogen levels were related to an increased risk of death, COPD-related hospitalization, and the development of COPD. 
Table 4 Proportion of subjects with the outcome of interest: death, any COPD-related hospitalization during follow-up, those missing follow-up spirometry, highest quartile of FEV, decline, and incident Stage 2 or higher COPD (among those free of COPD at baseline)

\begin{tabular}{|c|c|c|c|c|c|}
\hline Covariate & $\begin{array}{l}\text { Death } \\
n=20,192\end{array}$ & $\begin{array}{l}\text { COPD-related } \\
\text { hospitalization } \\
n=20,192\end{array}$ & $\begin{array}{l}\text { Missing follow-up } \\
\text { spirometry } \\
n=20,192\end{array}$ & $\begin{array}{l}\text { Highest quartile } \\
\text { of FEV, decline } \\
n=16,935\end{array}$ & $\begin{array}{l}\text { Incident } \\
\text { Stage } 2 \text { COPD } \\
n=14,848\end{array}$ \\
\hline \multicolumn{6}{|l|}{ Age } \\
\hline $45-49$ & 3.9 & I.I & 10.5 & 24.4 & 2.7 \\
\hline $50-54$ & 6.4 & 2.4 & 10.3 & 26.1 & 3.1 \\
\hline $55-59$ & 10.6 & 4.4 & 10.9 & 26.6 & 4.4 \\
\hline $60-64$ & 16.9 & 7.9 & 14.1 & 27.9 & 5.4 \\
\hline $65-68$ & 17.8 & 15.6 & 21.8 & 22.4 & 8.9 \\
\hline $69-72$ & 24.4 & 18.4 & 25.7 & 21.9 & 9.2 \\
\hline $73-76$ & 33.0 & 20.4 & 31.9 & 19.9 & 10.5 \\
\hline $77-80$ & 48.1 & 22.9 & 40.7 & 18.8 & 13.7 \\
\hline$>80$ & 72.1 & 19.4 & 60.1 & 18.8 & 10.7 \\
\hline \multicolumn{6}{|l|}{ Sex } \\
\hline Male & 11.7 & 6.0 & 15.8 & 18.6 & 4.5 \\
\hline Female & 18.8 & 9.3 & 16.8 & 33.3 & 5.3 \\
\hline \multicolumn{6}{|l|}{ Race-ethnicity } \\
\hline White & 14.9 & 8.6 & 14.9 & 26.1 & 5.4 \\
\hline Black & 14.5 & 3.2 & 21.5 & 21.1 & 3.1 \\
\hline \multicolumn{6}{|l|}{ Body mass index } \\
\hline$<20$ & 25.8 & 15.3 & 23.0 & 22.5 & 7.9 \\
\hline $20-25$ & 14.8 & 7.9 & 16.0 & 24.6 & 5.7 \\
\hline $25-30$ & 14.7 & 6.9 & 15.2 & 26.2 & 4.7 \\
\hline$>30$ & 13.4 & 6.6 & 17.2 & 24.4 & 4.0 \\
\hline \multicolumn{6}{|l|}{ Smoking status } \\
\hline Current smoker & 17.8 & 12.3 & 19.2 & 31.0 & 8.6 \\
\hline Former smoker & 16.3 & 8.7 & 16.1 & 26.3 & 5.1 \\
\hline Never smoker & 11.8 & 3.6 & 14.7 & 20.8 & 2.9 \\
\hline \multicolumn{6}{|l|}{ GOLD stage } \\
\hline Stage 3 or 4 & 44.8 & 46.5 & 38.3 & 19.6 & N/A \\
\hline Stage 2 & 23.5 & 19.6 & 23.5 & 25.5 & N/A \\
\hline Stage I & 21.6 & 10.6 & 19.6 & 31.7 & 15.0 \\
\hline Symptoms only & 13.0 & 4.3 & 14.4 & 27.0 & 2.6 \\
\hline Restrictive & 15.3 & 6.5 & 19.2 & 13.4 & 8.3 \\
\hline None & 8.2 & 1.8 & 11.0 & 26.6 & 1.6 \\
\hline \multicolumn{6}{|l|}{ Diabetes mellitus } \\
\hline Yes & 29.0 & 10.3 & 27.0 & 23.5 & 5.9 \\
\hline No & 12.8 & 7.1 & 14.7 & 25.3 & 4.8 \\
\hline \multicolumn{6}{|c|}{ Cardiovascular disease } \\
\hline Yes & 29.6 & 15.8 & 25.7 & 27.9 & 7.5 \\
\hline No & 12.2 & 6.0 & 14.6 & 24.7 & 4.5 \\
\hline \multicolumn{6}{|l|}{ Education level } \\
\hline$<12$ & 22.6 & 11.8 & 25.7 & 23.4 & 5.8 \\
\hline 12 years & 12.1 & 6.9 & 14.3 & 24.8 & 5.1 \\
\hline$>13$ years & 12.5 & 5.4 & 12.5 & 26.2 & 4.3 \\
\hline \multicolumn{6}{|l|}{ Fibrinogen $>393$} \\
\hline Yes & 28.5 & 14.8 & 29.1 & 25.3 & 8.4 \\
\hline No & 13.3 & 6.7 & 14.9 & 25.1 & 4.6 \\
\hline Total & 14.8 & 7.5 & 16.3 & 25.1 & 4.9 \\
\hline
\end{tabular}

Abbreviations: COPD, chronic obstructive pulmonary disease; $\mathrm{FEV}_{1}$, forced expiratory volume in I second.

Our findings are consistent with those of Dahl et $\mathrm{al}^{9}$ who showed that increased levels of plasma fibrinogen were associated with reduced lung function and increased risk of COPD, independent of smoking status. Jiang et $\mathrm{al}^{20}$ also found that higher levels of baseline fibrinogen were cross-sectionally associated with lower lung function and greater longitudinal declines in $\mathrm{FEV}_{1} / \mathrm{FVC}$ ratio in the elderly. Two population based studies ${ }^{21,22}$ showed that stable COPD patients have a pro-inflammatory state with increased levels of acute-phase reactants. Kalhan et $\mathrm{al}^{8}$ found 
Table 5 Quartiles of lung function decline among subjects who had baseline and follow-up pulmonary function measurement $(n=16,935)$ and baseline $F E V_{1}$, the mean annualized change in their absolute $F E V_{1}$, annualized FEV change as a percentage of the baseline value, and annualized FEV, change as a percentage of the baseline predicted FEV, value

\begin{tabular}{llllll}
\hline $\begin{array}{l}\text { FEV } \text {, change } \\
\text { quartiles }\end{array}$ & $\mathbf{n}$ & $\begin{array}{l}\text { Baseline FEV } \\
\text { (percent predicted) }\end{array}$ & $\begin{array}{l}\text { Change in FEV } \\
\text { (SD) }\end{array}$ & $\begin{array}{l}\text { Change in FEV } \text {, as }_{\text {percentage of baseline (SD) }} \\
\text { percentage of predicted (SD) }\end{array}$ & $\begin{array}{l}\text { Change in FEV as } \\
\text { perced }\end{array}$ \\
\hline 1 & 4322 & 98.1 & $-127(63)$ & $-4.7(2.6)$ & $-4.3(2.2)$ \\
2 & 4306 & 93.9 & $-61(10)$ & $-2.4(0.9)$ & $-2.2(0.5)$ \\
3 & 4307 & 91.2 & $-28(9)$ & $-1.2(0.6)$ & $-1.0(0.4)$ \\
4 & 4310 & 88.0 & $33(72)$ & $1.9(6.0)$ & $1.2(2.8)$ \\
\hline
\end{tabular}

Abbreviations: $\mathrm{FEV}_{1}$, forced expiratory volume in I second; SD, standard deviation.

that participants in the highest year 7 fibrinogen had greater $\mathrm{FEV}_{1}$ and FVC decline.

This analysis demonstrates that fibrinogen levels in this cohort were significantly related to a number of factors, including age, sex, race/ethnicity, current smoking status, overweight and obesity, presence of chronic diseases such as CVD, diabetes mellitus, and COPD. A previous study ${ }^{22}$ has shown that obstructive and restrictive lung diseases were predictors of increased levels of plasma fibrinogen. As fibrinogen levels were only determined at baseline we cannot speculate whether elevated fibrinogen caused COPD or
COPD caused elevated levels of fibrinogen. It is still unknown and uncertain how and why individuals with COPD develop systemic inflammation. Whatever is the mechanism of COPD development, previous studies have shown individuals with accelerated decline in lung function are at an increased risk of COPD hospitalizations in the future. Engstrom et al showed increased incidence of hospital admissions for COPD in those with raised fibrinogen. ${ }^{23}$

We have demonstrated an effect of elevated fibrinogen on mortality, COPD-hospitalizations, and incident Stage 2 COPD in the overall cohort (Table 6). The finding of elevated

Table 6 Results of unadjusted and fully adjusted logistic and Cox proportional hazards models predicting death, any COPD-related hospitalization during follow-up, those missing follow-up spirometry, highest quartile of FEV, decline, and incident Stage 2 or higher COPD (among those free of COPD at baseline), with fibrinogen (per $100 \mathrm{mg} / \mathrm{dL}$ increase) or fibrinogen $>393 \mathrm{mg} / \mathrm{dL}$ as the main predictors

\begin{tabular}{|c|c|c|c|c|}
\hline Outcome & $\begin{array}{l}\text { Risk per } 100 \mathrm{mg} / \mathrm{dL} \\
\text { increase in fibrinogen } \\
\text { (unadjusted) }\end{array}$ & $\begin{array}{l}\text { Risk per } 100 \mathrm{mg} / \mathrm{dL} \\
\text { increase in fibrinogen } \\
\text { (adjusted)* }\end{array}$ & $\begin{array}{l}\text { Risk among subjects } \\
\text { with fibrinogen } \\
\text { levels }>393 \mathrm{mg} / \mathrm{dL} \\
\text { (unadjusted) }\end{array}$ & $\begin{array}{l}\text { Risk among subjects } \\
\text { with fibrinogen } \\
\text { levels }>393 \mathrm{mg} / \mathrm{dL} \\
\text { (adjusted)* }\end{array}$ \\
\hline $\begin{array}{l}\text { Death } \\
\mathrm{n}=20,192 \\
\text { Hazard ratio } \\
\text { ( } 95 \% \text { confidence interval) }\end{array}$ & $1.69(1.62,1.77)$ & I.3I (I.24, I.38) & $2.39(2.18,2.62)$ & $1.54(1.39,1.70)$ \\
\hline $\begin{array}{l}\text { COPD-related hospitalization } \\
\mathrm{n}=20,192 \\
\text { Hazard ratio } \\
\text { ( } 95 \% \text { confidence interval) }\end{array}$ & $1.76(1.66,1.87)$ & $1.30(1.21,1.39)$ & $2.52(2.22,2.87)$ & $1.45(1.27,1.67)$ \\
\hline $\begin{array}{l}\text { Missing follow-up spirometry } \\
\mathrm{n}=20,192 \\
\text { Odds ratio } \\
\text { ( } 95 \% \text { confidence interval) }\end{array}$ & $1.67(1.58,1.76)$ & $1.25(1.18,1.33)$ & $2.35(2.12,2.6 I)$ & $1.52(1.35,1.71)$ \\
\hline $\begin{array}{l}\text { Highest quartile of } \\
\mathrm{FEV} \text {, decline } \\
\mathrm{n}=16,935 \\
\text { odds ratio } \\
\text { ( } 95 \% \text { confidence interval) }\end{array}$ & $1.00(0.95,1.06)$ & 1.07 (I.01, I.I4) & I.0I $(0.89,1.14)$ & I.08 $(0.95,1.23)$ \\
\hline $\begin{array}{l}\text { Incident Stage } 2 \text { COPD } \\
\mathrm{n}=14,848 \\
\text { Odds ratio } \\
\text { ( } 95 \% \text { confidence interval) }\end{array}$ & $1.49(1.34,1.65)$ & $1.17(1.03,1.33)$ & $1.90(1.52,2.38)$ & $1.36(1.07,1.74)$ \\
\hline
\end{tabular}

Note: *Adjusted for age, sex, race, education level, body mass index, smoking status, diabetes mellitus, cardiovascular disease, and GOLD stage. Abbreviations: COPD, chronic obstructive pulmonary disease; $\mathrm{FEV}_{1}$, forced expiratory volume in I second. 


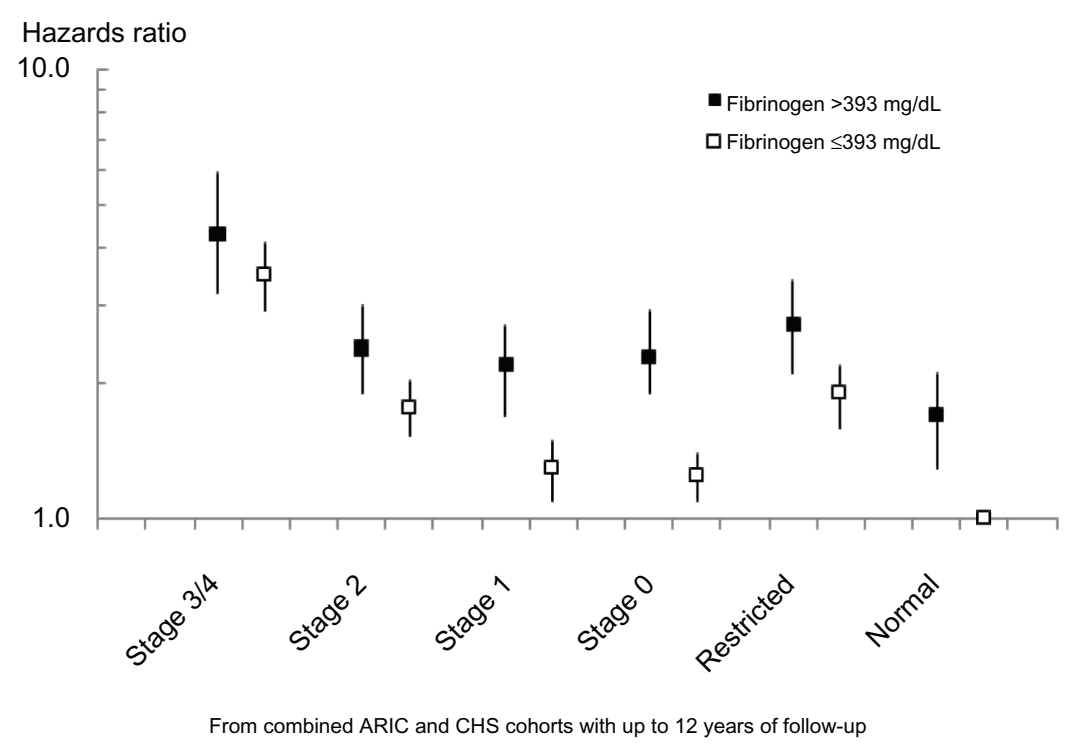

Figure I Risk of mortality by modified GOLD stage and elevated fibrinogen level.

Abbreviations: ARIC, Atherosclerosis Risk in Communities Study; CHS, Cardiovascular Health Study; GOLD, Global Initiative on Chronic Obstructive Lung Disease.

fibrinogen and the higher risk of mortality, COPDhospitalizations, and incident Stage 2 COPD raises an option that fibrinogen could be used as a biomarker of disease activity in COPD and potential target for therapeutic interventions.

To our knowledge, this is one of the few studies with follow-up data, and although fibrinogen level was only available at baseline, partial temporal association of fibrinogen and lung function can be taken into account, although other cohort studies with lung specimens, exacerbations, and imaging are needed to validate the findings. The study has adequate sample size and power. Bias due to investigator's knowledge of disease or risk factor seems unlikely since plasma fibrinogen was measured without the knowledge of lung function test results or disease status of subjects.

This analysis has several limitations. Analysis was only done using baseline fibrinogen levels, as follow-up fibrinogen levels were not available on all subjects. Another limitation is the unavailability of post-bronchodilator lung function- measurement, information on COPD exacerbations other than hospitalized exacerbations, and lung imaging for COPD. Not all subjects completed pulmonary function testing, biasing our sample towards a healthier population.

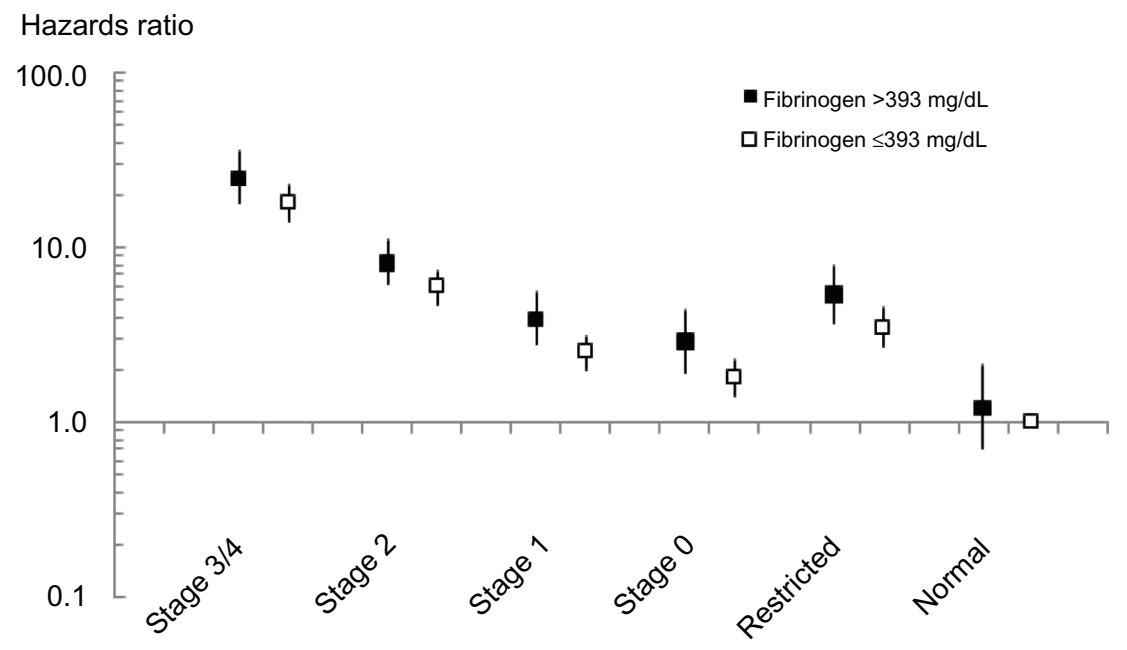

From combined ARIC and CHS cohorts with up to 12 years of follow-up

Figure 2 Risk of chronic obstructive pulmonary disease-related hospitalization by modified GOLD stage and elevated fibrinogen level.

Abbreviations: ARIC, Atherosclerosis Risk in Communities Study; CHS, Cardiovascular Health Study; GOLD, Global Initiative on Chronic Obstructive Lung Disease. 


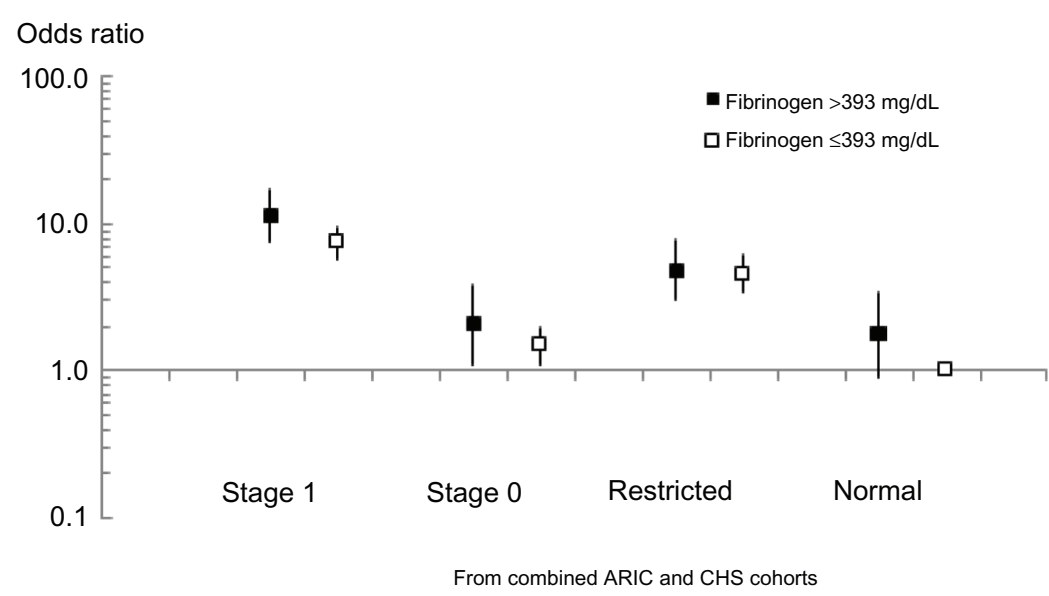

Figure 3 Risk of incident chronic obstructive pulmonary disease by modified GOLD stage and elevated fibrinogen level.

Abbreviations: ARIC, Atherosclerosis Risk in Communities Study; CHS, Cardiovascular Health Study; GOLD, Global Initiative on Chronic Obstructive Lung Disease.

In addition, although we have adjusted for potential confounders there remains residual confounding due to COPD disease pathology based on genetic constitution, nutritional intake, environmental exposures, alcohol intake, and other infections causing systemic inflammation. These findings need to be replicated in other cohorts, including those with longitudinal measurements of fibrinogen.

\section{Conclusion}

In conclusion, we have demonstrated that elevated plasma fibrinogen was associated with COPD; predicting higher risk of mortality, COPD-hospitalizations, and incident Stage 2 disease. Fibrinogen can serve as a biomarker of the systemic component of COPD and may provide an option for targeting of interventions to patients with evidence of systemic inflammation or provide a means of stratifying patients in clinical trials. Future research is needed to evaluate whether targeted reduction in plasma fibrinogen levels will result in better COPD outcomes.

\section{Authors' contributions}

DMM and DV conceived of the study, and participated in its design and coordination, completed the data analyses, and helped to draft the manuscript. HM and RTS participated in the design and coordination of the study and helped to draft the manuscript. All authors read and approved the final manuscript.

\section{Acknowledgments}

The authors thank the staff and participants in the ARIC Study and the CHS for their important contributions. The ARIC Study and CHS are conducted and supported by the National
Heart Lung and Blood Institute in collaboration with the ARIC Investigators. This manuscript was not prepared in collaboration with investigators of the ARIC or the CHS and does not necessarily reflect the opinions or views of the ARIC or the National Heart Lung and Blood Institute. The authors would also like to thank Ms Susan Mittenzwei and Ms Rebecca Copeland for their assistance in this project. Funding for the analysis was provided by GlaxoSmithKline.

\section{Disclosures}

DMM has received research funding from GlaxoSmithKline, Novartis, Boehringer-Ingelheim, and Pfizer and has worked as a consultant or advisor for GlaxoSmithKline, Novartis, Boehringer-Ingelheim, Astra-Zeneca, and Pfizer. DV declares no conflicts of interest. HM and RTS are employees and shareholders of GlaxoSmithKline.

\section{References}

1. Mannino DM, Buist AS. Global burden of COPD: risk factors, prevalence, and future trends. Lancet. 2007;370(9589):765-773.

2. Minino AM, Xu J, Kochanek KD. Death in the United States, 2008. Natl Vital Stat Rep. 2010;59(1):1-72.

3. Burrows B, Fletcher CM, Heard BE, Jones NL, Wootliff JS. The emphysematous and bronchial types of chronic airways obstruction. A clinicopathological study of patients in London and Chicago. Lancet. 1966;1(7442):830-835.

4. Fletcher C, Peto R, Tinker CM, Speizer FE. The Natural History of Chronic Bronchitis and Emphysema. Oxford, UK: Oxford University Press; 1976.

5. Anthonisen NR. The British hypothesis revisited. Eur Respir J. 2004;23(5):657-658.

6. Vestbo J, Prescott E. Update on the "Dutch hypothesis" for chronic respiratory disease. Thorax. 1998;53 Suppl 2:S15-S19.

7. Larsson K. Inflammatory markers in COPD. Clin Respir J. 2008;2 Suppl 1: S84-S87.

8. Kalhan R, Tran BT, Colangelo LA, et al. Systemic inflammation in young adults is associated with abnormal lung function in middle age. PLoS One. 2010;5(7):e11431 
9. Dahl M, Tybjaerg-Hansen A, Vestbo J, Lange P, Nordestgaard BG. Elevated plasma fibrinogen associated with reduced pulmonary function and increased risk of chronic obstructive pulmonary disease. $\mathrm{Am}$ J Respir Crit Care Med. 2001;164(6):1008-1011.

10. Groenewegen KH, Postma DS, Hop WC, Wielders PL, Schlosser NJ, Wouters EF. Increased systemic inflammation is a risk factor for COPD exacerbations. Chest. 2008;133(2):350-357.

11. Jousilahti P, Salomaa V, Hakala K, Rasi V, Vahtera E, Palosuo T. The association of sensitive systemic inflammation markers with bronchial asthma. Ann Allergy Asthma Immunol. 2002;89(4):381-385.

12. Higashimoto Y, Iwata T, Okada M, Satoh H, Fukuda K, Tohda Y. Serum biomarkers as predictors of lung function decline in chronic obstructive pulmonary disease. Respir Med. 2009;103(8):1231-1238.

13. The Atherosclerosis Risk in Communities (ARIC) Study: design and objectives. The ARIC investigators. Am J Epidemiol. 1989;129(4):687-702.

14. Fried LP, Borhani NO, Enright P, et al. The Cardiovascular Health Study: design and rationale. Ann Epidemiol. 1991;1(3):263-276.

15. Papp AC, Hatzakis H, Bracey A, Wu KK. ARIC hemostasis study - I. Development of a blood collection and processing system suitable for multicenter hemostatic studies. Thromb Haemost. 1989;61(1):15-19.

16. Chambless LE, McMahon R, Wu K, Folsom A, Finch A, Shen YL. Short-term intraindividual variability in hemostasis factors. The ARIC Study. Atherosclerosis Risk in Communities Intraindividual Variability Study. Ann Epidemiol. 1992;2(5):723-733.
17. Cushman M, Cornell ES, Howard PR, Bovill EG, Tracy RP. Laboratory methods and quality assurance in the Cardiovascular Health Study. Clin Chem. 1995;41(2):264-270.

18. American Thoracic Society. ATS statement - Snowbird workshop on standardization of spirometry. Am Rev Respir Dis. 1979;119(5): 831-838.

19. Hankinson JL, Odencrantz JR, Fedan KB. Spirometric reference values from a sample of the general US population. Am J Respir Crit Care Med. 1999;159(1):179-187.

20. Jiang R, Burke GL, Enright PL, et al. Inflammatory markers and longitudinal lung function decline in the elderly. Am J Epidemiol. 2008;168(6):602-610.

21. Garcia-Rio F, Miravitlles M, Soriano JB, et al. Systemic inflammation in chronic obstructive pulmonary disease: a population-based study. Respir Res. 2010;11:63.

22. Mannino DM, Ford ES, Redd SC. Obstructive and restrictive lung disease and markers of inflammation: data from the Third National Health and Nutrition Examination. Am J Med. 2003;114(9):758-762.

23. Engstrom G, Segelstorm N, Ekberg-Aronsson M, Nilsson PM, Lindgarde F, Lofdahl CG. Plasma markers of inflammation and incidence of hospitalisations for COPD: results from a population-based cohort study. Thorax. 2009;64(3):211-215.

\section{Publish your work in this journal}

The International Journal of COPD is an international, peer-reviewed journal of therapeutics and pharmacology focusing on concise rapid reporting of clinical studies and reviews in COPD. Special focus is given to the pathophysiological processes underlying the disease, intervention programs, patient focused education, and self management protocols.

\section{Dovepress}

This journal is indexed on PubMed Central, MedLine and CAS. The manuscript management system is completely online and includes a very quick and fair peer-review system, which is all easy to use. Visit http://www.dovepress.com/testimonials.php to read real quotes from published authors. 